\title{
Effect of carvedilol versus nebivolol on insulin resistance among non-diabetic, non- ischemic cardiomyopathy with heart failure
}

\author{
Yasser Gaber Metwally ${ }^{1 *}$, Heba Kamal Sedrak ${ }^{2}$ and Inass Fahiem Shaltout ${ }^{2}$
}

\begin{abstract}
Background: Although B-blockers provide unequivocal benefits in heart failure (HF) management, some B-blockers worsen insulin resistance. It will be a promising strategy to recruit such a B blocker that did not worsen or can even improve insulin resistance (IR).

So, this study aimed to assess the effect of two of the third-generation B-blockers (carvedilol versus nebivolol) on insulin sensitivity state in non-diabetic patients with non-ischemic cardiomyopathy with heart failure.

Results: Out of 43 patients enrolled, 58.1\% represented the carvedilol group while $41.9 \%$ represented the nebivolol group. Nebivolol improves insulin resistance-related variables (fasting glucose, fasting insulin, and HOMA-IR; $P<$ $0.001,0.01$, and 0.01 respectively). The percentage of change at homeostasis model of assessment (HOMA-IR), indicative of insulin sensitivity status, between baseline versus at 3-months follow-up level of intra-group comparison was increased by $4.58 \%$ in the carvedilol arm whereas it was decreased by $11.67 \%$ in the nebivolol arm, and the difference on the intragroup level of comparison was significant $(P<0.001$ and 0.01 respectively).

Conclusion: Nebivolol improves insulin resistance-related variables. Nebivolol may be recommended as the $B$ blocker of the first choice for those with non-ischemic cardiomyopathy heart failure with evident insulin resistance; however, larger scaled prospective multicenter randomized trials are needed for confirming our favorable results.
\end{abstract}

Keywords: Carvedilol, Nebivolol, Insulin resistance, Heart failure

\section{Background}

Myocardial systolic dysfunction is associated with sympathetic hyperactivity evidenced by increased plasma norepinephrine (NE) level, central sympathetic outflow, and NE plasma spillover [1]. Measurement of cardiac NE plasma release using isotope dilution method indicates that in untreated heart failure patients, cardiac NE spillover is increased as much as 50 times similar to levels seen in healthy hearts during maximal exercise [2]. However, in contrast to increased muscle sympathetic nerve activity and NE spillover, patients with heart failure with reduced ejection

\footnotetext{
* Correspondence: yassercardio@gmail.com

'Department of Cardiology, Faculty of Medicine, Zagazig University, Zagazig, Egypt

Full list of author information is available at the end of the article
}

fraction (HFrEF) may have decreased NE concentration inside the cardiac cells, together with a reduction of postsynaptic beta-receptor density [3]. However, it should be realized that plasma NE level does not necessarily reflect the sympathetic activity level in skeletal muscle [4]. The neurohormonal hyperactivity associating HfrEF represents a compensatory mechanism to maintain cardiac output. The neuronal limb of such response is represented by the sympathetic nervous system (SNS), whereas the humoral limb is represented by the renin-angiotensin aldosterone axis [5]. The overactivation of the sympathetic nervous system in congestive heart failure (CHF) patients is thought to contribute to hyperinsulinism and insulin resistance (IR) [6]. A moderate increase in plasma NE has been observed to reduce glucose tolerance, and insulin sensitivity may be accomplished by increased lipolysis and free fatty acid levels [7]. 
Moreover, a small increase in plasma NE has been reported to increase fasting blood glucose through transient stimulation of basal hepatic glucose output without altering basal glucose utilization, insulin, or glucagon secretion [8]. On the other hand, insulin does also stimulate the SNS. According to animal and human studies, it has been demonstrated that short-term insulin infusion stimulates the SNS activity [9]. It is evident that acute physiological as well as pharmacological euglycemic hyperinsulinemia increase plasma catecholamine concentration [10]. Furthermore, it is documented that hypertensive patients show an enhanced SNS activity in response to insulin [11]. Hyperinsulinemia may therefore also influence adrenergic activity, contributing to further insulin-resistance worsening (vicious circle).

Evident data suggest that heart failure may not only precipitate insulin resistance but also lead to IR worsening [12]. Although B-blockers provide unequivocal benefits in heart failure management including improving survival, some B-blockers worsen insulin resistance [13, 14]. However, it will be a promising strategy in heart failure therapy to recruit such a B blocker that did not worsen or can even improve insulin resistance. We hypothesized that nebivolol could have a better effect on insulin resistance than carvedilol among non-diabetic, non-ischemic cardiomyopathy with heart failure. Accordingly, this study aimed to investigate the effect of carvedilol versus nebivolol on insulin resistance among non-diabetic, non-ischemic cardiomyopathy with heart failure.

\section{Methods}

\section{Study population}

This study was conducted from March 2018 to May 2020.

Forty-three consecutive patients with non-diabetic, non-ischemic cardiomyopathy with CHF were enrolled in this study. Patients were eligible if mild to moderate $\mathrm{CHF}$ present ejection fraction (EF\%) is between 30 and 40\%, New York Heart Association Classification (NYHA class) is ranged between I and II, and age is between 40 and 80 years. Diabetes mellitus, known ischemic heart disease or previous CABG, active myocarditis, significant valve lesion, alcoholics, severe CHF $(\mathrm{EF}<25 \%)$, NYHA class III and IV, patients in need for CCU admission, or patients that had been admitted to CCU within the last 3 months, patients who are fibrillating or with sustained ventricular tachycardia, patients with chronic kidney disease or with active liver disease alanine aminotransferase $(\mathrm{ALT})>3$ folds, and patients with contraindication to Bblockers were exclusion criteria.

They were randomly assigned by a computer program. Patients were assigned to one of the two arms of the study either to receive carvedilol (carvedilol group $n=25$ ( or nebivolol group; $n=18$ ).

\section{Study protocol}

After 2-weeks wash-out period (e.g., the patients received no B blocker treatment for a period of 2 weeks prior to their inclusion, to eliminate previous B blocker effect before starting carvedilol/nebivolol), our study protocol started including the following both at the beginning of the study as well as at the study end: NYHA class assessment, vitals (pulse/minute, blood pressure), body mass index (BMI), EF\% (by Simpson Method), 6-minute walk test [15], routine laboratory investigations, fasting glucose level, glycosylated hemoglobin ( $\mathrm{HbA} 1 \mathrm{C} \%)$, and fasting insulin of the blood samples collected for measurement of glucose and insulin. Plasma glucose was measured by glucose oxidase method with a Beckman glucose analyzer, and plasma insulin concentrations were determined by radioimmunoassay.

\section{Measurement of insulin sensitivity}

The estimate of insulin resistance by homeostasis model of assessment (HOMA-IR) derives an estimate of insulin sensitivity from the mathematical modeling of fasting glucose and insulin concentrations [16]. In comparison to the euglycemic clamp, the HOMA-IR model is an easy, practical, and inexpensive method for assessing IR. We applied the HOMA-IR in non-diabetic participants using the following formula [17]: fasting insulin level $(\mu \mathrm{U} / \mathrm{ml}) \times$ fasting glucose $(\mathrm{mg} / \mathrm{dl}) / 405$, subjects whose values exceeded the 75th percentile (i.e., 2.0) were considered to have insulin resistance (HOMA-IR index) [18].

\section{Measurement of norepinephrine}

After $30 \mathrm{~min}$ rest, $9 \mathrm{ml}$ of blood was drawn from an antecubital vein through the intravenous cannula, into prechilled tubes containing $15 \mathrm{ml}$ EGTA (ethylene-glycol-tetra acetic-acid) and $12 \mathrm{mg}$ glutathione. The tubes were kept on ice before and after blood sampling and were immediately centrifuged at $4{ }^{\circ} \mathrm{C}$ and $3000 \mathrm{rpm}$ for $15 \mathrm{~min}$, and then stored at $-80^{\circ} \mathrm{C}$ until analysis by high-performance liquid chromatography [19]. All blood samples from the same patient were analyzed within the same setup.

\section{Measurement of plasminogen activator inhibitor (PAI-1)}

Blood samples were collected on ice and centrifuged immediately at $0{ }^{\circ} \mathrm{C}$ for $20 \mathrm{~min}$. All plasma or serum were separated and stored at $-80^{\circ} \mathrm{C}$ until the time of assay. Blood for measurement of PAI-1 was collected in vacutainer tubes containing acidified $0.105 \mathrm{M}$ sodium citrate (Becton Dickinson, Rutherford, NJ), as the use of anticoagulant minimizes the contribution of platelet activation to PAI-1 antigen concentrations. PAI-1 antigen level was determined using 2-site-enzyme-linked immunosorbent assays (Imulyse, Biopol AB).

The drug dose regimen for the carvedilol arm, a starting dose of $3.125 \mathrm{mg}$ bid, was given; then, the dose was uptitrated to a target dose of $25 \mathrm{mg}$ bid or the maximally 
tolerated dose for 12 weeks. For the nebivolol arm, a starting dose of $2.5 \mathrm{mg} /$ day was given; then, the dose was uptitrated to a target dose of $10 \mathrm{mg} /$ day or the maximally tolerated dose for 12 weeks. The further lines of treatment for heart failure were given according to the standard guidelines [20]. After 12 weeks clinical, laboratory followup, data were obtained through the outpatient department (OPD) visits.

The primary endpoint was evaluating the relative effects of those two B-blockers on insulin resistance as assessed by insulin resistance index) HOMA-IR) at the baseline and after 3 months treatment.

\section{Statistical analysis}

The continuous variables were expressed in mean \pm SD while discrete variables were expressed in percentage. The differences in continuous variables were checked for statistical significance by $t$ test as appropriate; the differences in the discrete variables were checked for statistical significance by $X^{2}$ test. The percentage of change at HOMA-IR between baselines versus at 3 months followup level of intragroup comparison was done. $P$ value < 0.05 was considered significant. The statistical analysis was performed using SPSS.11 for Windows (SPSS Inc., Chicago, IL, USA).

\section{Results}

Out of 43 patients enrolled, 58.1\% represented the carvedilol group while $41.9 \%$ represented the nebivolol group.
The demographic and clinical characteristics of our study population are shown in Table 1 .

No significant differences were found regarding age, weight, BMI, waist circumference, gender, triglyceride, high-density lipoprotein (HDL), uric acid, hemoglobin (HB) percentage, percentage of the use of loop diuretics, RAS blockers, digoxin, or aspirin. However, the study group showed significantly higher percentage of the use of aldosterone blockers among the carvedilol group $(P=0.036)$.

The intragroup versus intergroup comparison of variables at the baseline versus at 3-months follow-up is shown in Tables 2 and 3.

No significant differences were found neither on intragroup nor on intergroup comparison level (both at the baseline and at follow-up) regarding B blocker compliance or plasminogen activator inhibitor level. Likewise, no significant differences were found on intergroup comparison level (both at the baseline and at follow-up) regarding heart rate, blood pressure, NYHA class, EF\%, or 6 min walk test.

The fasting glucose, fasting insulin, and HOMA-IR showed no significant difference on intragroup comparison (for carvedilol group only) and on intergroup comparison at baseline (for the two groups); however, these 3 variables were significantly lower among the nebivolol group (at 3 months follow-up only) both on intragroup and intergroup comparison $(P<0.001,0.01$, and 0.01$)$ respectively (HOMA-IR changes are shown in Fig. 1).

The norepinephrine level was significantly lower in the carvedilol group (G1) on intragroup level of comparison on 3 months follow-up $(P=0.002)$. On the other hand,

Table 1 Demographic, baseline clinical, and medications among the two groups

\begin{tabular}{|c|c|c|c|}
\hline & Carvedilol group $(N=25)$ & Nebivolol group $(N=18)$ & $P$ value \\
\hline Age & $50.5 \pm 10.5$ & $50.9 \pm 9.6$ & 0.89 \\
\hline Wt $(\mathrm{kg})$ & $83.3 \pm 12$ & $81.4 \pm 10$ & 0.58 \\
\hline $\mathrm{BMI}\left(\mathrm{kg} / \mathrm{m}^{2}\right)$ & $37.0 \pm 6.1$ & $36.8 \pm 4.3$ & 0.9 \\
\hline Waist circum(cm ) & $118.6 \pm 10.5$ & $117.3 \pm 9.9$ & 0.68 \\
\hline Male gender & $14(56 \%)$ & $10(55.6 \%)$ & 0.8 \\
\hline Smokers & $8(33 \%)$ & $4(22.2 \%)$ & 0.48 \\
\hline TG (mg/dl) & $132 \pm 4.5$ & $134 \pm 3.5$ & 0.12 \\
\hline $\mathrm{HDL}(\mathrm{mg} / \mathrm{dl})$ & $38 \pm 6.2$ & $39 \pm 5.3$ & 0.59 \\
\hline Uric $\operatorname{acid}(\mathrm{mg} / \mathrm{dl})$ & $8.1 \pm 2.6$ & $8.0 \pm 2.3$ & 0.89 \\
\hline $\mathrm{Hb} \%$ (gm) & $13.5 \pm 1.2$ & $13.0 \pm 2.1$ & 0.36 \\
\hline \multicolumn{4}{|l|}{ Medications } \\
\hline Loop diuretic & $17(68 \%)$ & $12(66.7 \%)$ & 0.93 \\
\hline Aldosterone blocker & $15(60 \%)$ & $5(27.8 \%)$ & $0.036^{*}$ \\
\hline RAS blocker & $23(92 \%)$ & 17 (94.4\%) & 0.99 \\
\hline Digoxin & $6(24 \%)$ & $4(22.2 \%)$ & 0.99 \\
\hline ASA & $19(76 \%)$ & $14(77.8 \%)$ & 0.99 \\
\hline
\end{tabular}

$A S A$ aspirin, $B M I$ body mass index, $H B$ hemoglobin, $H D L$ high-density lipoprotein, $R A S$ renin-angiotensin-system, $T G$ triglyceride ${ }^{*} P$ is significant 
Table 2 Intra- versus intergroup comparison of variables at the baseline versus at 3 months follow-up among the two groups

\begin{tabular}{|c|c|c|c|c|c|c|c|}
\hline & & \multicolumn{2}{|l|}{ G1 } & \multicolumn{2}{|l|}{ G2 } & \multicolumn{2}{|c|}{ Inter-group } \\
\hline & & Baseline & After 3 months & Baseline & After 3 months & ${ }^{c} p$ & ${ }^{\mathrm{d} P}$ \\
\hline \multicolumn{2}{|l|}{ 1. $\mathrm{HR}$} & $102 \pm 7$ & $71 \pm 5$ & $103 \pm 9$ & $70 \pm 6$ & & \\
\hline \multicolumn{2}{|c|}{ Intragroup $t$ test } & \multicolumn{2}{|l|}{${ }^{\mathrm{a}} P<0.001^{*}$} & \multicolumn{2}{|l|}{${ }^{b} P<0.001^{*}$} & 0.68 & 0.55 \\
\hline \multirow{2}{*}{\multicolumn{2}{|c|}{ 2. BP }} & $137 \pm 7$ & $130 \pm 8$ & $135 \pm 6$ & $130 \pm 9$ & & \\
\hline & & $85 \pm 9$ & $80 \pm 10$ & $32 \pm 5$ & $80 \pm 6$ & & \\
\hline \multicolumn{2}{|c|}{ Intragroup $t$ test } & \multicolumn{2}{|c|}{${ }^{\mathrm{a}} P<0.001^{*},<0.001^{*}$} & \multicolumn{2}{|c|}{${ }^{\mathrm{b}} P<0.001^{*},<0.02^{*}$} & 0.21 & 0.68 \\
\hline \multirow[t]{2}{*}{ 3. NYHA } & Class I & $20(80 \%)$ & 19 (76 \%) & $12(66.7 \%)$ & $14(77.8 \%)$ & & \\
\hline & Class ॥ & $6(24 \%)$ & $6(24 \%)$ & $6(33.3 \%)$ & $4(22.2 \%)$ & & \\
\hline \multicolumn{2}{|c|}{ Intragroup $t$ test } & \multicolumn{2}{|l|}{${ }^{\mathrm{a}} P=0.03^{*}$} & \multicolumn{2}{|l|}{${ }^{\mathrm{b}} P=0.046^{*}$} & 0.85 & 0.99 \\
\hline \multicolumn{2}{|l|}{ 4. EF\% } & $39 \pm 4.2$ & $42 \pm 3.0$ & $38.9 \pm 3.2$ & $41.8 \pm 3.3$ & & \\
\hline \multicolumn{2}{|c|}{ Intragroup $t$ test } & \multicolumn{2}{|l|}{${ }^{\mathrm{a}} P<0.001^{*}$} & \multicolumn{2}{|l|}{${ }^{b} p<0.001^{*}$} & 0.93 & 0.84 \\
\hline \multicolumn{2}{|c|}{ 5. B blocker compliance } & $24(96 \%)$ & $24(96 \%)$ & $17(94 \%)$ & $17(94 \%)$ & & \\
\hline \multicolumn{2}{|c|}{ Intragroup $t$ test } & \multicolumn{2}{|l|}{${ }^{\mathrm{a}} p>0.99$} & \multicolumn{2}{|l|}{${ }^{b} p>0.99$} & 0.99 & 0.99 \\
\hline \multicolumn{2}{|l|}{ 6. $\mathrm{HbAlc}$} & $5.8 \pm 0.8$ & $5.9 \pm 0.3$ & $5.9 \pm 0.6$ & $5.3 \pm 0.2$ & & \\
\hline \multicolumn{2}{|c|}{ Intragroup $t$ test } & \multicolumn{2}{|l|}{${ }^{\mathrm{a}} P=0.76$} & \multicolumn{2}{|l|}{${ }^{\mathrm{b}} P<0.001^{*}$} & 0.55 & $<0.001^{*}$ \\
\hline \multicolumn{2}{|c|}{ 7. Fasting glucose (mg/dl) } & $102 \pm 14$ & $103 \pm 9$ & $103 \pm 9$ & $97 \pm 7$ & & \\
\hline \multicolumn{2}{|c|}{ Intragroup $t$ test } & \multicolumn{2}{|l|}{${ }^{\mathrm{a}} P=0.73$} & \multicolumn{2}{|l|}{${ }^{b} p<0.001^{*}$} & 0.31 & $0.023^{*}$ \\
\hline \multicolumn{2}{|c|}{ 8. Plasma insulin (IU/ml) } & $5.3 \pm 3.2$ & $5.4 \pm 3.9$ & $5.4 \pm 4.1$ & $3.5 \pm 0.23$ & & \\
\hline Intragro & & ${ }^{\mathrm{a}} \mathrm{P}=0.62$ & & ${ }^{\mathrm{b}} p=0.01^{*}$ & & 0.92 & $0.046^{*}$ \\
\hline 9. $\mathrm{HOMA}-$ & & $1.31 \pm 0.29$ & $1.37 \pm 0.3$ & $1.37 \pm 0.3$ & $1.21 \pm 0.08$ & & \\
\hline Intragro & & ${ }^{\mathrm{a}} P=0.41$ & & ${ }^{\mathrm{b}} P=0.01^{*}$ & & 0.52 & $0.01^{*}$ \\
\hline 10. Plasme & ine $(\mathrm{pg} / \mathrm{ml} \%)$ & $530 \pm 159$ & $436 \pm 30$ & $531 \pm 171$ & $499 \pm 102$ & & \\
\hline Intragro & & ${ }^{a} P=0.002^{*}$ & & ${ }^{b} p=0.08$ & & 0.98 & $0.019^{*}$ \\
\hline 11. Plasmi & or I (ng/ml) & $9.9 \pm 3.2$ & $9.8 \pm 2.7$ & $10.2 \pm 2.5$ & $10.1 \pm 3.3$ & & \\
\hline Intragro & & ${ }^{\mathrm{a}} P=0.37$ & & ${ }^{b} p=0.81$ & & 0.74 & 0.75 \\
\hline $\begin{array}{l}\text { HR heart ra } \\
\text { ejection fra } \\
{ }^{*} P \text { is signifi } \\
{ }^{\mathrm{a}} P \text { intragro } \\
{ }^{\mathrm{b}} P \text { intragro } \\
{ }^{C} P \text { intragro } \\
{ }^{d} P \text { intergro }\end{array}$ & $\begin{array}{l}\text { ressure, } \mathrm{HbA1C} \\
\mathrm{p} 1, \mathrm{G} 2 \text { group } 2 \\
\text { of group } 1 \\
\text { of group } 2 \\
\text { of group } 1 \text {; int } \\
\text { of group } 1 \text { and }\end{array}$ & oglobin, $H C$ & and aroun 2 at ba & & & & \\
\hline
\end{tabular}

Table 3 Intra- versus intergroup comparison of 6 min walk test at the baseline versus at 3 months follow-up for the two groups

\begin{tabular}{|c|c|c|c|c|c|c|}
\hline & \multicolumn{2}{|l|}{ G1 } & \multicolumn{2}{|l|}{ G2 } & \multicolumn{2}{|c|}{ Intergroup } \\
\hline & Baseline & After 3 months & Baseline & After 3 months & ${ }^{c} p$ & ${ }^{d} P$ \\
\hline \multicolumn{7}{|c|}{ A. Mean distance walked $(\mathrm{m})$} \\
\hline & $322 \pm 104$ & $404 \pm 108$ & $326 \pm 100$ & $407 \pm 104.0$ & & \\
\hline & ${ }^{\mathrm{a}} P<0.001^{*}$ & & ${ }^{b} P<0.001^{*}$ & & 0.9 & 0.93 \\
\hline \multicolumn{7}{|c|}{ B. No. of patients walked $<300 \mathrm{~m}$} \\
\hline & $9(36 \%)$ & $3(12 \%)$ & 7 (38.9\%) & $2(11.1 \%)$ & & \\
\hline Intragroup $t$ test & ${ }^{\mathrm{a}} p=0.031^{*}$ & & ${ }^{b} p=0.063^{*}$ & & 0.85 & 0.99 \\
\hline
\end{tabular}

*P is significant

${ }^{\text {a }} P$, intragroup comparison of group 1

${ }^{\mathrm{b}} \mathrm{P}_{\text {, intragroup comparison of group } 2}$

${ }^{\mathrm{c}} P$, intragroup comparison of group 1 ; intergroup comparison of group 1 and group 2 at baseline

${ }^{d} P$, intergroup comparison of group 1 and group 2 after 3 months 


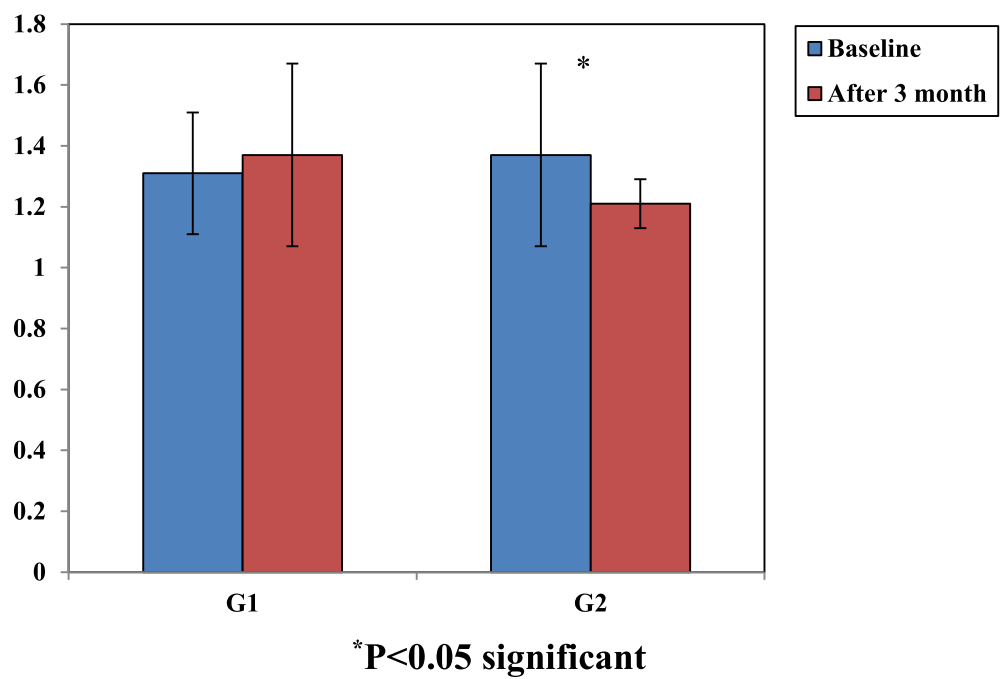

Fig. 1 Homeostatic model of assessment for insulin resistance in both groups. X-axis refers to the studied groups, Y-axis refers to the HOMA-IR value; G1, group 1; G2, group 2

its level showed no significant difference at the nebivolol group (G2) neither on intragroup nor on intergroup comparison level with the nebivolol group (G2).

The PA-I level showed non-significant difference in both carvedilol group (G1) and nebivolol group (G2) whether on intragroup or intergroup level of comparison.

The following variables were significantly improved (at 3 months follow-up) on intragroup level of comparison, e.g., NYHA class, EF\%, mean distance walked, and number of patients walked $<300 \mathrm{~m}(P=0.03, P=0.046, P<$ 0.001, $P<0.001, P<0.001, P<0.001, P=0.031$, and $P=$ 0.063 ) respectively. Likewise, blood pressure and heart rate were also significantly decreased on intragroup level of comparison $(P<0.001, P<0.001, P<0.001,<0.02, P$ $<0.001,<0.001)$ respectively. The percentage of change at HOMA-IR, indicative of insulin sensitivity status, between baseline versus at 3 months follow-up level of intragroup comparison is shown in Table 4. The percentage of change was increased by $4.58 \%$ at the carvedilol arm whereas was decreased by $11.67 \%$ at the nebivolol arm, and the difference on the intra-group level of comparison was significant $(P<0.001$ and 0.01$)$ respectively.

\section{Discussion}

The interrelationship between HF and IR, plasma norepinephrine, and B-blockers was discussed above [2-11, 14].

Results of our study demonstrated that nebivolol but not carvedilol improves insulin sensitivity while carvedilol but not nebivolol decreases plasma norepinephrine level. Our results of favorable effect on nebivolol on insulin sensitivity in HF patients can be explained by Manrique and colleagues [21]; they conducted an experimental study on insulin resistance Sprague-Dawley rat model treated with nebivolol for 3 weeks; they assessed HOMA-IR index as well as nicotinamide adenine dinucleotide phosphate (NADPH) oxidase activity (NADPH is an insulin metabolic signaling in skeletal muscle) before and after nebivolol

Table $\mathbf{4}$ Comparison between both groups

\begin{tabular}{|c|c|c|c|c|}
\hline & \multicolumn{4}{|l|}{ Studied groups } \\
\hline & \multicolumn{2}{|c|}{ Carvedilol group $(n=25)$} & \multicolumn{2}{|c|}{ Nebivolol group $(n=18)$} \\
\hline & Before & After & Before & After \\
\hline HOMA-IR & $1.31 \pm 0.29$ & $1.37 \pm 0.3$ & $1.37 \pm 0.3$ & $1.21 \pm 0.08$ \\
\hline$\wedge P$ & $P<0.001$ & & $P=0.01$ & \\
\hline Percent of change & Increase (4.58\%) & & Decreased (11.67\%) & \\
\hline Norepinephrine & $530 \pm 159$ & $436 \pm 30$ & $531 \pm 171$ & $499 \pm 102$ \\
\hline$\wedge P$ & $P<0.002$ & & $P=0.08$ & \\
\hline Percent of change & Decreased ( 17.73\%) & & Decreased (6.02\%) & \\
\hline
\end{tabular}

HOMA-IR homeostasis model of assessment

$\wedge$ Paired $t$ test

${ }^{*} P$ is significant 
treatment. They concluded that treatment with nebivolol was associated with improvement in insulin resistance with decreased NADPH oxidase activity level. A previous study [22] demonstrated that the improvement in insulin sensitivity is closely associated with decreased NADPH oxidase activity in skeletal muscle.

Previous clinical trials had investigated the value of Bblockers in CHF [23-25].

One study [23] conducted a prospective doubleblinded, placebo-controlled randomized study on 46 CHF patients who received carvedilol or placebo to investigate whether treatment with carvedilol alter insulin sensitivity or not. They found that neither insulin sensitivity nor plasma norepinephrine had been significantly altered. Differently from this study, the present study demonstrated a significant decrease in the plasma norepinephrine level among the carvedilol group.

Ferrua et al. [24] reported that carvedilol significantly reduced HOMA-index in non-diabetic CHF patients; this was contradictory to our results.

Another pilot study investigated the nebivolol effect in CHF patients reported; after 6 weeks period of treatment, plasma catecholamine remained unchanged at rest and during exercise [25]. Ayers et al. [26] reported that nebivolol has a neutral effect on IR in metabolic syndrome (Met S) patients. Apart from studies on carvedilol and nebivolol, De Groote and colleagues [27] investigated 3 months bisoprolol effect in patients with stable congestive heart failure; they reported EF\% improvement with a significant decrease in plasma norepinephrine level.

The decrease of plasma norepinephrine with carvedilol found in our study could be explained by a sympathoinhibitory action through blocking peripheral $\mathrm{B}$ receptor [28]. Grundemar et al. [29] reported that carvedilol blocks B1, $\mathrm{B} 2$, and $\alpha 1$ adrenergic receptors at a higher dose. Also, it does not modulate B1 receptor (e.g., no upregulation or downregulation), thus, exerting much anti adrenergic properties compared to the selective B-blockers.

Although there was a significantly higher use of aldosterone antagonist (a drug known to improve insulin resistance in patients with chronic heart failure [30]) among the carvedilol group, however, this did not attenuate carvedilol effect on IR (e.g., carvedilol takes the upper hand).

Our result demonstrated normal serum PAI-1 level, with no significant differences between the two groups of our study population. According to some recent studies, the relation between PAI-1 and the Met S criteria needed for diagnosis may not always be straight forward and needs more study [31].

\section{Conclusion}

Nebivolol improved the insulin resistance-related variables (fasting glucose, fasting insulin, and HOMA-IR) while carvedilol was neutral. Meanwhile, carvedilol decreased plasma norepinephrine level while nebivolol was neutral. Lastly, both B-blockers improved the hemodynamicsrelated variables by the same extent. Nebivolol may be recommended as the B blocker of the first choice for nonischemic cardiomyopathy heart failure patients complicated by insulin resistance; however, larger scaled prospective multicenter randomized trials are needed for confirming our favorable results.

\section{Study limitations}

Firstly, our sample size was relatively small; a larger scaled prospective multicenter randomized trial is needed. Secondly, long-term follow-ups are not studied.

\section{Abbreviations}

ALT: Alanine aminotransferase; BMI: Body mass index; CABG: Coronary artery bypass grafting; CHF: Congestive heart failure; RAS blocker: Renin-angiotensin system blocker; EGTA: Ethylene-glycol-tetra acetic-acid; EF: Ejection fraction; HB: Heart block; HFrEF: Heart failure with reduced ejection fraction; HDL: High-density lipoprotein; HOMA-IR: Homeostasis model of assessment; HbA1c: Glycosylated hemoglobin; IR: Insulin resistance; NE: Norepinephrine; NADPH: Nicotinamide adenine dinucleotide phosphate; NYHA: New York Heart Association Classification; PAl: Plasminogen activator inhibitor; OPD: Outpatient department; SNS: Sympathetic nervous system

\section{Acknowledgements}

Not applicable

\section{Authors' contributions}

All authors contributed significantly in the research. Y.G.M. did actively the following steps: concept, design, definition of intellectual content, literature search, experimental studies, clinical studies, data acquisition, data analysis, statistical analysis, manuscript preparation, manuscript editing, manuscript review, guarantor, while H.K.S. did actively the following steps: design, definition of intellectual content, literature search, experimental studies, clinical studies, data analysis, manuscript preparation, manuscript editing, manuscript review. And lastly, I.F.S. did actively the following steps: design, definition of intellectual content, literature search, experimental studies, clinical studies, data analysis, statistical analysis, manuscript preparation, manuscript editing, manuscript review. All authors read and approved the final manuscript.

\section{Funding}

All authors declare that they have no financial or special source of funds.

\section{Availability of data and materials}

All data and material of the research are available if requested.

\section{Ethics approval and consent to participate}

An informed written consent, in advance, had been given from all patients that was approved by the independent medical ethics of the University of Twente and the institutional review board of the participating centers (cardiology and internal medicine departments, Zagazig and Cairo faculty of medicine) (no reference number).

\section{Consent for publication \\ Not applicable}

Competing interests

All authors declare that they have no competing interest.

\section{Author details}

'Department of Cardiology, Faculty of Medicine, Zagazig University, Zagazig, Egypt. ${ }^{2}$ Department of Internal Medicine, Faculty of Medicine, Cairo

University, Cairo, Egypt. 
Received: 23 July 2020 Accepted: 15 September 2020

Published online: 29 September 2020

\section{References}

1. Pepper GS, Lee RW (1999) Sympathetic activation in heart failure and its treatment with $\beta$-blockade. Archives Internal Med 159(3):225-234

2. Morris MJ, Cox HS, Lambert GW, Kaye DM, Jennings GL, Meredith IT, Esler MD (1997) Region-specific neuropeptide $Y$ overflows at rest and during sympathetic activation in humans. Hypertension 29(1):137-143

3. Regitz V, Leuchs B, Bossaller C, Sehested J, Rappolder M, Fleck E (1991) Myocardial catecholamine concentrations in dilated cardiomyopathy and heart failure of different origins. Eur Heart J 12(suppl_D):171-174

4. Tomiyama H, Kushiro T, Abeta H, Ishii T, Takahashi A, Furukawa L, Otsuka Y (1994) Kinins contribute to the improvement of insulin sensitivity during treatment with angiotensin converting enzyme inhibitor. Hypertension 23(4):450-455

5. Dzau VJ, Colucci WS, Hollenberg NK, Williams GH (1981) Relation of the renin-angiotensin-aldosterone system to clinical state in congestive heart failure. Circulation 63(3):645-651

6. Scherrer U, Sartori C (1997) Insulin as a vascular and sympathoexcitatory hormone: implications for blood pressure regulation, insulin sensitivity, and cardiovascular morbidity. Circulation 96(11):4104-4113

7. Marangou AG, Alford FP, Ward G, Liskaser F et al (1988) Hormonal effects of norepinephrine on acute glucose disposal in humans: a minimal model analysis. Metabolism 37(9):885-891

8. Sacca L, Morrone G, Cicala M, Corso G, Ungaro B (1980) Influence of epinephrine, norepinephrine, and isoproterenol on glucose homeostasis in normal man. J Clin Endocrinol Metabolism 50(4):680-684

9. Lembo, G., Napoli, R., Capaldo, B., Rendina, V., laccarino, G., Volpe, M., ..\& Saccà, L. Abnormal sympathetic overactivity evoked by insulin in the skeletal muscle of patients with essential hypertension. J Clin Investigation 1992; 90(1), 24-29.

10. O'Hare JA, Minaker KL, Meneilly GS, Rowe JW, Pallotta JA, Young JB (1989) Effect of insulin on plasma norepinephrine and 3, 4-dihydroxyphenylalanine in obese men. Metabolism 38(4):322-329

11. Grassi, G., Seravalle, G., Cattaneo, B. M., Bolla, G. B., Lanfranchi, A., Colombo, M., ... Mancia, G. Sympathetic activation in obese normotensive subjects. Hypertension 1995; 25(4), 560-563.

12. Swan JW, Anker SD, Walton C, Godsland IF, Clark AL, Leyva F, Coats AJ (1997) Insulin resistance in chronic heart failure: relation to severity and etiology of heart failure. J Am College Cardiol 30(2):527-532

13. Jacob S, Rett K, Wicklmayr M, Agrawal B, Augustin HJ, Dietze GJ (1996) Differential effect of chronic treatment with two beta-blocking agents on insulin sensitivity: the carvedilol-metoprolol study. J Hypertension 14(4):489-494

14. Pollare T, Lithell H, Selinus I, Berne C (1989) Sensitivity to insulin during treatment with atenolol and metoprolol: a randomised, double blind study of effects on carbohydrate and lipoprotein metabolism in hypertensive patients. Brit Med J 298(6681):1152-1157

15. Enright PL, McBurnie MA, Bittner $V$, Tracy RP, McNamara R, Arnold A, Newman AB (2003) The 6-min walk test: a quick measure of functional status in elderly adults. Chest 123(2):387-398

16. Honing ML, Morrison PJ, Banga JD, Stroes ES, Rabelink TJ (1998) Nitric oxide availability in diabetes mellitus. Diabetes/Metabolism Review 14(3):241-249

17. Wallace TM, Levy JC, Matthews DR (2004) Use and abuse of HOMA modeling. Diabetes Care 27(6):1487-1495

18. Balkau, B., Charles, M.A. Comment on the provisional report from the WHO consultation European group for the study of insulin resistance (EGIR). Diabet Med 1999; 16: 442-443.

19. Eriksson BM, Persson BA (1982) Determination of catecholamines in rat heart tissue and plasma samples by liquid chromatography with electrochemical detection. J Chromaogr 228:143-154

20. Ponikowski P, Voors AA, Anker SD et al (2016) 2006 ESC Guidelines for the diagnosis and treatment of acute and chronic heart failure: the task force for the diagnosis and treatment of acute and chronic heart failure of the European Society of Cardiology (ESC) developed with the special contribution of the Heart Failure Association (HFA) of the ESC. Eur Heart J 37(27):2129-2200

21. Manrique C, Lastra G, Habibi J, Pulakat L, Schneider R, Durante W, WhaleyConnell A (2011) Nebivolol improves insulin sensitivity in the TGR (Ren2) 27 rat. Metabolism 60(12):1757-1766

22. Hitomi, H., Kiyomoto, H., Nishiyama, A., Hara, T., Moriwaki, K., Kaifu, K., ...\& Kohno, M. Aldosterone suppresses insulin signaling via the downregulation of insulin receptor substrate-1 in vascular smooth muscle cells. Hypertension 2007 50(4), 750-755.
23. Refsgaard J, Thomsen C, Andreasen F, Gøtzsche O (2002) Carvedilol does not alter the insulin sensitivity in patients with congestive heart failure. Eur J Heart Failure 4:445-453

24. Ferrua, S., Bobbio, M., Catalano, E., Grassi, G., Massobrio, N., Pinach, S., ... \& Trevi, G. P. . Does carvedilol impair insulin sensitivity in heart failure patients without diabetes?. J Cardiac Failure 2005; 11(8), 590-594.

25. Lechat, P. H., Boutelant, S., Komajda, M., Gagey, et al. Pilot study of cardiovascular effects of nebivolol in congestive heart failure. Drug Investigation 1991; 3(1), 69-81.

26. Ayers K, Byrne LM, DeMatteo A, Brown NJ (2012) Differential effects of nebivolol and metoprolol on insulin sensitivity and plasminogen activator inhibitor in the metabolic syndrome. Hypertension 59(4):893-898

27. De Groote, P., Delour, P., Lamblin, N., et al .Effects of bisoprolol in patients with stable congestive heart failure. In Annales de Cardiologie et d'Angeiologie 2004 (Vol. 53, No. 4, pp. 167-170).

28. Azevedo, E. R., Kubo, T., Mak, S., Al-Hesayen, A., Schofield, A., Allan, R., ... \& Parker, J. D. . Nonselective versus selective $\beta$-adrenergic receptor blockade in congestive heart failure: differential effects on sympathetic activity. Circulation 2001 104(18), 2194-2199.

29. Grundemar L, Håkanson R (1993) Multiple neuropeptide $Y$ receptors are involved in cardiovascular regulation. Peripheral and central mechanisms. General Pharmacology: The Vascular System 24(4):785-796

30. Ogino K, Kinugasa Y, Kato M, Yamamoto K, Hisatome I, Anker SD, Doehne W (2014) Spironolactone, not furosemide, improved insulin resistance in patients with chronic heart failure. Int J Cardiol 171(3):398-403

31. Kodaman N, Aldrich MC, Sobota R et al (2016) Plasminogen activator inhibitor-1 and diagnosis of the metabolic syndrome in a West African population. J Am Heart Assoc 5(10):e003867

\section{Publisher's Note}

Springer Nature remains neutral with regard to jurisdictional claims in published maps and institutional affiliations.

\section{Submit your manuscript to a SpringerOpen ${ }^{\circ}$ journal and benefit from:}

- Convenient online submission

- Rigorous peer review

- Open access: articles freely available online

High visibility within the field

- Retaining the copyright to your article

Submit your next manuscript at $\boldsymbol{\nabla}$ springeropen.com 